\title{
APORTES INICIAIS PARA UMA PROTEÇÃO JURÍDICA DOS SERVIÇOS ECOSSISTÊMICOS
}

Rodrigo Kempf da Silva

Mestrando em Direito pela Universidade do Vale do Rio dos Sinos (UNISINOS).Graduado em Direito pela Universidade do Vale do Rio dos Sinos (UNISINOS). Advogado.

Email: rodrigokempfdasilva@gmail.com

Délton Winter de Carvalho

Pós-Doutor em Direito, UniversityofCaliforniaat Berkeley, USA. Doutor em Direito pela Universidade do Vale do Rio dos Sinos (UNISINOS). Mestre em Direito pela Universidade do Vale do Rio dos Sinos (UNISINOS). Professor do Programa de Pós-Graduação em Direito na Universidade do Vale do Rio dos Sinos (UNISINOS), níveis mestrado e doutorado. Email: deltonwc@via-rs.net

\section{RESUMO}

O presente artigo tem por objetivo analisar os principais aspectos dos serviços ecossistêmicos. A partir de uma análise multidisciplinar, serão demonstrados esses serviços sob o âmbito ecológico, geográfico e econômico para, então, demonstrar o seu aspecto jurídico. Para analisar este último aspecto, iremos apresentar duas formas de proteção dos serviços ecossistêmicos: o pagamento por serviços ambientais e a infraestrutura verde no enfrentamento de desastres ambientais. Após, serão demonstrados os oito princípios elaborados por J. B. Ruhl que auxiliam na criação e elaboração de políticas que preservem esses serviços. A pesquisa foi realizada por meio de análise doutrinária nacional e internacional, de legislação e de julgados brasileiros.

Palavras-chave: Serviços Ecossistêmicos; Direito; Infraestrutura Verde; Pagamento por serviços ambientais; Multidisciplinaridade. 


\title{
INITIAL CONTRIBUTIONS TO A LEGAL PROTECTION OF ECOSYSTEM SERVICES
}

\begin{abstract}
This article aims to analyse the main aspects of ecosystem services. From a multidisciplinary analysis, these services will be demonstrated on the ecological, geographic and economic scope and then demonstrate their legal aspect. To analyze this last aspect, we will present two forms of protection of the ecosystem services: the payment for ecosystem services and the use of green infrastructure to mitigate environmental disasters. After, will be shown the J. B. Ruhl's eight principles that assist the creation and development of ecosystem services policies. This research was conducted through analysis of national and international doctrine, brazilia nlegislation and judicial decisions.
\end{abstract}

Keywords: Ecosystem services; Law; Green infrastructure; Payment for ecosystem services; Multidisciplinarity. 


\section{INTRODUÇÃO}

O presente trabalho tem por objetivo demonstrar a importância dos serviços ecossistêmicos e como eles são protegidos pelo sistema jurídico. Analisando-se a complexidade que envolve a matéria, verificarse-á de que forma os serviços ecossistêmicos podem ser integrados no sistema jurídico.

A primeira parte irá analisar a matéria a partir de três perspectivas: a biológica, destacando a importância de se reconhecer a existência dos serviços ecossistêmicos e os benefícios produzidos pela humanidade; a geográfica, que delimita a origem, o caminho percorrido e os beneficiários dos serviços; e a econômica, que tenta elaborar métodos de valoração dos serviços ecossistêmicos

$\mathrm{Na}$ segunda parte, será analisado o âmbito jurídico desses serviços. Serão vistos, para isso, dois casos específicos: o pagamento por serviços ambientais e a noção de infraestrutura verde para a redução do risco de desastres ambientais.

Por fim, serão analisados os oito princípios criados por J. B. Ruhl que pretendem estipular alguns critérios a serem utilizados ao se criar políticas de proteção e manutenção dos serviços ecossistêmicos.

\section{Serviços ecossistêmicos: conceitos e complexidade}

Serviços ecossistêmicos são os "[...] benefícios que as pessoas obtêm dos ecossistemas" (MILLENNIUM ECOSYSTEM ASSESSMENT, 2005 , p. v). Este conceito tem sua origem nos estudos de economia ambiental (CONSTANZA, 1997; DAILY, 1997), os quais chamam a atenção para a importância da manutenção e preservação dos ecossistemas, visto que estes são responsáveis por produzir diversos serviços essenciais para a sustentabilidade humana ${ }^{1}$.

Classicamente, entende-se que os ecossistemas são bens de uso comum do povo, protegidos pela Constituição $\mathrm{Federal}^{2}$. O conceito de serviços ecossistêmicos traz uma nova perspectiva a esta ideia, demonstrando que os ecossistemas são capazes de produzir bens e produtos para a humanidade, contribuindo com seu desenvolvimento (CARVALHO, 1 Robert Constanza (1997) apontou que o valor médio de 17 serviços ecossistêmicos estipulados na época era de quase duas vezes o PIB mundial de 1994.

2 Art. 225, da Constituição Federal:“Todos têm direito ao meio ambiente ecologicamente equilibrado, bem de uso comum do povo e essencial à sadia qualidade de vida, impondo-se ao Poder Público e à coletividade o dever de defendê-lo e preservá- lo para as presentes e futuras gerações". 
2015). Para se identificar, delimitar e proteger os serviços ecossistêmicos, é necessária uma atuação multidisciplinar envolvendo ciência, direito, economia e política (DAILY, 2009). Neste sentido, um aprofundamento sobre as complexidades envolvendo a temática se faz necessário, a fim de se possibilitar reconhecer os pressupostos requeridos para a proteção dos serviços ecossistêmicos.

1.1. Ecossistemas, função ecológica, capital natural e serviços ecossistêmicos

Com o intuito de descrever o que são serviços ecossistêmicos, é necessário, inicialmente, abordar o local onde estes se encontram, bem como diferenciá-los dos ecossistemas e do capital natural. Assim, será explicado, a partir de uma perspectiva ecológica, como são formados os serviços ecossistêmicos.

Ecossistemas são considerados sistemas complexos, formados por diversos componentes em relação aos quais as ações de um "[...] pode afetar muitos outros, inclusive o próprio agente" (RUHL, KRAFT, LANT, 2007, p. 18). Por conta do intenso e contínuo fluxo de componentes (que podem, ou não, gerar serviços ecossistêmicos), é praticamente impossível analisar todo ecossistema separando os respectivos elementos que o compõem. Em face dessa dificuldade de se analisar sistemas complexos ${ }^{3}$, estudiosos do tema destacam que os sistemas operam visando ao equilíbrio e, em se tratando de sistemas ecológicos (ecossistemas), o equilíbrio se dá por sua resistência (resistir a perturbações externas) e resiliência ${ }^{4}$ (capacidade de se recuperar de perturbações).

Por conta de sua característica "aberta" - que inclui a absorção de componentes externos ao ecossistema, como a luz solar; processamentos internos, como a fotossíntese; e a produção de novos componentes externos, como o oxigênio -, há um desafio de se definir o que seria, científica e politicamente, útil para estabelecer limites dos ecossistemas. De acordo

3 Citando Constanza, os autores Ruhl, Kraft e Lant apontam quatro características dos sistemas complexos: 1) forte interação, nem sempre linear, entre seus componentes; 2) dificuldade de se distinguir causa de efeito; 3) significativas descontinuidades temporais e locais; e 4) impossibilidade de se considerar que a agregação de um determinado componente ao sistema terá um resultado esperado (RUHL, KRAFT, LANT, 2007, p. 18-19).

4 Sobre a resiliência, ver: CARVALHO, DéltonWinter de; DAMACENA, Fernanda Dalla Libera. Direito dos desastres. Porto Alegre: Livraria do Advogado, 2013, p. 59-63. E também: IPCC. Managing the risks of extreme events and disasters to advance climate change adaptation. A special report of working group I and II of the Intergovernmental Panel on Climate Change. Cambridge: Cambridge University Press, 2012, p. 34. 
com Ruhl, Kraft e Lant, são quatro os principais problemas oferecidos pela "natureza aberta" dos ecossistemas para definir os limites (RUHL; KRAFT; LANT, 2007, p. 21):

1) diversos ecossistemas menores podem existir dentro de um maior; 2) ecossistemas são interligados e frequentemente difíceis de se separar; 3) limites dos ecossistemas expandem e contraem ao longo do tempo, por conta de influências naturais e antropogênicas; e 4) ecossistemas são definidos ecologicamente em vez de serem definidos por legislação ou pela administração ${ }^{5}$.

Os componentes responsáveis por estruturarem e manterem os ecossistemas são chamados de funções ecológicas (ecological functions). Segundo Constanza, funções ecológicas são responsáveis pela manutenção do habitat natural e pela estrutura de um ecossistema (CONSTANZA et al, 1997). Eventos que degradam a estrutura de um ecossistema (como a pesca predatória, por exemplo) acabam afetando negativamente as funções ecológicas que mantêm a sustentabilidade desse ecossistema, prejudicando os serviços ecossistêmicos e, respectivamente, o desenvolvimento humano. (RUHL, KRAFT, LANT, 2007).

Vários autores caracterizam os processos, fluxos e funções ocorridos dentro dos ecossistemas como capital natural (GRETCHEN, 2015; RUHL, KRAFT, LANT, 2007; CONSTANZA, 1997, 2014). Isto é, o capital natural estrutura os ecossistemas e pode gerar serviços ecossistêmicos.

Dessa forma, de uma maneira muito sucinta, percebe-se que os ecossistemas são sistemas extremamente complexos, em relação aos quais vários processos que ocorrem em seu interior são realizados para sustentálos, criando estabilidade. Desses processos, os fluxos de processos ocorridos nos ecossistemas (capital natural) podem gerar serviços ecossistêmicos. Entretanto, por conta de uma falta de linearidade nos ecossistemas (complexidade em se identificar os serviços), traçar os seus limites (para se estabelecer políticas ambientais, por exemplo) torna-se uma tarefa muito difícil (RUHL, KRAFT, LATN, 2007), exigindo um grande esforço e cooperação de diversas áreas (DAILY, 2009).

Os serviços ecossistêmicos são produzidos a partir dos processos que ocorrem no interior dos ecossistemas. Pode-se dizer que,

5 Tradução livre de: “(1) several smaller ecosystem may exist within a larger one, (2) ecosystem are interlinked and often difficult to separate, (3) boundaries of ecosystem expand and contract over time in response to natural and anthropogenic influences, and (4) ecosystems are ecologically rather than legislatively or administratively established features". 
quando existirem beneficios originados a partir dos ecossistemas para a humanidade, está-se diante de serviços ecossistêmicos. Dentre os conceitos existentes na literatura sobre serviços ecossistêmicos, podemos mencionar que estes são classificados como os benefícios para as pessoas originados dos ecossistemas (CONSTANZA, 1997), ou "[...] as condições e processos que os ecossistemas geram - ou ajudam a gerar-que beneficiam as pessoas" (DAILY, 2015) e, também "[...] os benefícios que as pessoas obtêm dos ecossistemas" (MILLENNIUM ECOSYSTEM ASSESSMENT, 2005, p. v).

Necessário destacar que, quando se fala em serviços ecossistêmicos, deve estar claro que o componente humano está presente. Só há serviços ecossistêmicos quando existirem os beneficiários destes serviços (alguma pessoa, uma comunidade, um país etc), no caso, a humanidade. Nas palavras de Ruhl, Kraft e Lant (2007, p. 27) "[...] processos e funções ecológicos não geram serviços ecossistêmicos até que eles sejam usados por pessoas" (grifo nosso)!

Para se saber de que forma o capital natural (componentes gerados pelas funções e pelos processos no interior dos ecossistemas) pode gerar serviços ecossistêmicos e como esses serviços são essenciais para a humanidade, faz-se necessário um exame multidisciplinar que tente descrever: i) o uso feito pelo serviço; ii) a importância dada (e a percepção) a esses serviços pelos provedores e beneficiários dos serviços; iii) quais os modos disponíveis para proteger os serviços; iv) como instituições responsáveis pela proteção ambiental devem atuar (DAILY, et al, 2009, p. 24-27).Ou seja, serviços ecossistêmicos são tão complexos quanto a própria noção de ecossistema e seu uso demanda uma nova percepção pela coletividade de sua importância, sua formação (visto que são resultados de diversos processos e funções de um ou mais ecossistemas) e sua forma de conservação ${ }^{6}$.

Por conta da ampla gama de atuação dos serviços ecossistêmicos, eles são, normalmente, divididos em categorias, conforme seu respectivo benefício ao bem-estar humano. Dentre as diversas categorias existentes ${ }^{7}$, 6 Nas palavras de Ruhl, Kraft e Lant, esses serviços são muito menos flexíveis que serviços comercializados. Eles "[...] estão onde estão e são o que são, a menos que se alterem os processos de sua formação" e alterar seus processos pode ser prejudicial não apenas no fornecimento de um determinado serviço ecossistêmico, como também em outros serviços, conhecidos ou não, gerados por ecossistemas interligados ao alterado (RUHL; KRAFT; LANT, 2011, p. 32).

7 Gretchen Daily, por exemplo, os classifica em cinco categorias: produção de bens; processos de regeneração; processos de estabilização; processos de vida; e opções de preservação. Outros autores, como Holmund e Hammer, classificam os serviços ecossistêmicos em duas categorias principais: serviços fundamentais para a humanidade e ecossistemas; e serviços derivados de demanda (que satisfa- 
a mais conhecida é aquela feita pelo Millennium EcosystemAssessment, que dividiu os serviços ecossistêmicos em quatro categorias: serviços de provisão, de regulação, de cultura e de suporte (Millennium Ecosystem Assessment, 2005, p. 40, 50).

Os $i$ ) serviços de provisão (provisioning services) são aqueles que contribuem diretamente com a sobrevivência do ser humano, oferecendo produtos essenciais à vida, como comida, água, madeira e fonte de energia; ii) serviços de regulação (regulating services) são aqueles benefícios provindos de processos regulatórios dos próprios ecossistemas. É o caso de processos biológicos que regulam a qualidade do ar, fazem a regulação do clima, o controle de erosão, de cheias e de desastres naturais; iii) serviços culturais (cultural services) são serviços imateriais originados do meioambiente, como fontes de reflexão, recreação e experiências estéticas - questões como percepção local, valores sociais e hereditários são alguns desses exemplos; e iv) serviços de apoio (supporting services) são serviços que não são percebidos diretamente, pois auxiliam na formação dos outros serviços, como por exemplo: formação do solo, fotossíntese e formação primária de certos produtos ${ }^{8}$. Correspondem ao também chamado capital natural.

Os serviços ecossistêmicos interagem com o bem-estar humano por diversas formas e em diversas intensidades. Estes possuem, assim, enorme importância para o bem-estar humano, visto que atuam de forma extremamente diversificada, conforme disposto na figura a seguir:

zem os desejos humanos) (RUHL; KRAFT; LANT, 2011, p. 25-26).

8 Processo de erosão pode ser tanto um serviço ecossistêmico de apoio, como de regulação, conforme a observação que se fizer, quando se levar em consideração o tempo e o impacto. 


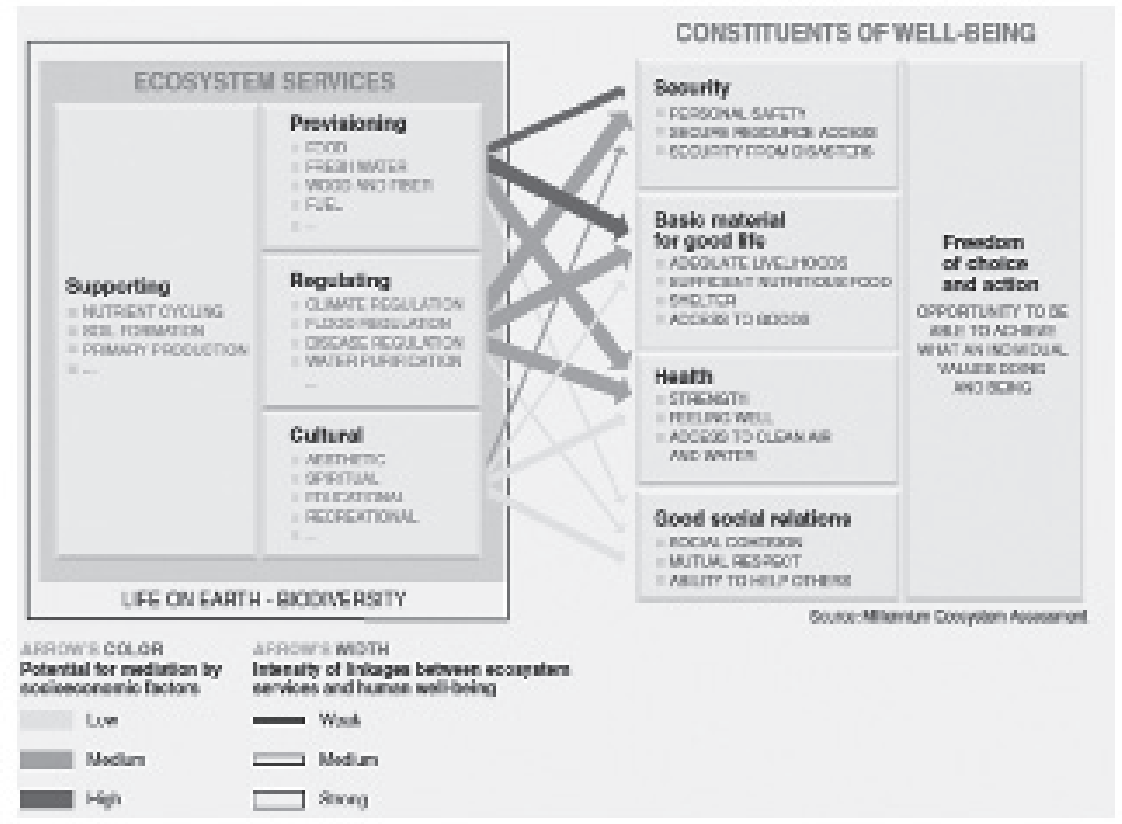

Fonte: Millennium Ecosystem Assessment, 2005.

Desta maneira, serviços ecossistêmicos têm-se demonstrado como possuidores de uma enorme importância ecológica para a humanidade. Também, destaca-se que são de grande complexidade para definir a relação entre a origem dos serviços (capital natural) e toda a gama de beneficiários (humanidade, de diversas maneiras). O recente aumento no interesse e o consequente aprofundamento dos estudos sobre a matéria poderão servir para auxiliar na descrição destes serviços, auxiliando na elaboração de diversas políticas ambientais. Entretanto, não basta apenas o conhecimento ecológico para que se estabeleçam políticas públicas de proteção e promoção dos serviços ecossistêmicos. Serviços ecossistêmicos devem ser estudados de forma multidisciplinar, envolvendo outras áreas do conhecimento (como a Geografia, a Economia e o Direito, por exemplo) para que se tenha uma proteção efetiva (RUHL; KRAFT; LANT, 2007).

Em estudo recente, Constanza (2014) identificou que os serviços ecossistêmicos não são utilizados diretamente pela humanidade, a partir do capital natural. O que ocorre, na verdade, é um processo de integração entre o capital humano (existência de pessoas), o capital social (a comunidade à qual as pessoas pertencem) e o capital construído (ambiente construído pela 
comunidade) aos serviços ecossistêmicos, gerando bem-estar, conforme demonstra a imagem abaixo reproduzida:

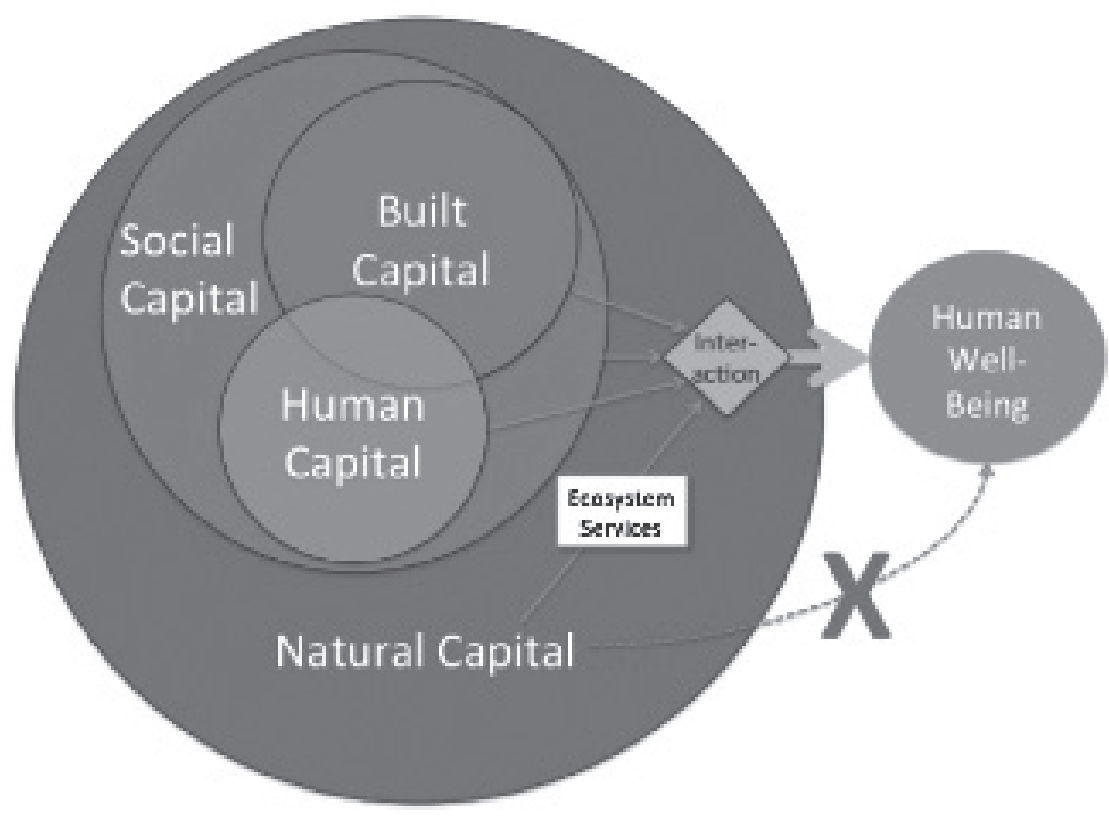

Fonte: CONSTANZA, 2014

Percebe-se, dessa forma, que os serviços ecossistêmicos possuem uma enorme relevância para a humanidade, por oferecerem serviços e produtos essenciais para a vida humana. Contudo, estes são, também, marcados pela complexidade no que diz respeito à sua descrição causal, identificação dos beneficiários, remuneração dos provedores e quantificação de benefícios, por exemplo. Além da dificuldade em se reconhecer quais são os serviços existentes, outra questão é posta para os decisores responsáveis pelas demandas envolvendo ecossistemas e seus serviços: sua delimitação geográfica e temporal. Isso porquea identificação da área de abrangência onde os serviços são produzidos e o modo como os serviços perpetuam temporalmente são essenciais para se preservar os ecossistemas e seus serviços. 
1.2. Dificuldades na delimitação dos serviços ecossistêmicos: escalas geográficas e temporais

Enquanto a ecologia dos serviços ecossistêmicos se propõe a identificar quais são os serviços e como eles refletem no bem-estar humano, a geografia dos serviços ecossistêmicos tenta delimitar e compreender i) a fonte do serviço, ii) a forma como ele é distribuído e iii) onde/para quem os serviços são distribuídos. Esses componentes assumem diferentes características, conforme os padrões espaciais e temporais analisados (RUHL; KRAFT; LANT, 2007).

A complexidade dos serviços ecossistêmicos demonstra que estes são gerados em escalas espaciais e temporais nem sempre semelhantes àquelas em que os processos ecológicos e as funções ecológicas ocorrem em um ecossistema. Ou seja, o serviço ecossistêmico correspondente pode existir em outro local e em outro momento.

As escalas importam para que haja a formulação de políticas de proteção dos serviços ecossistêmicos, bem como paraque se determinem aspectos voltados à proteção jurídica desses serviços. As escalas podem ser espaciais e temporais. Conforme a escolha da escala espacial utilizada para o serviço ecossistêmico, a interação será percebida, também, em níveis sociais, políticos e econômicos distintos. Seria o caso, por exemplo, de se analisar os serviços ecossistêmicos de uma bacia hidrográfica (escala regional), seus fornecedores e beneficiários, abrangendo assim toda a região que se beneficia dos serviços provenientes dos ecossistemas existentes nesta bacia. Neste caso ilustrativo, analisar-se-iam a economia de cada região e seus diversos aspectos sociais e políticos. Do mesmo modo, analisando-se os serviços ecossistêmicos em uma escala local (um banhado, por exemplo), verificar-se-iam as questões referentes ao município e suas características sociais, econômicas e políticas (RUHL; KRAFT; LANT, 2007).

Atenta-se ao fato de que não há uma hierarquia entre as escalas. Uma escala que for considerar serviços ecossistêmicos em um âmbito federal, por exemplo, não é mais importante do que uma escala que consideraria o âmbito local dos serviços. E, ainda quanto à complexidade dos ecossistemas e de seus serviços, gerenciá-los sem considerar os outros níveis de escalas prejudica a otimização dos serviços. Isso porque serviços ecossistêmicos se relacionam de forma dinâmica, envolvendo diversas escalas espaciais distintas para o fornecimento de um serviço específico. 
Por isso, uma análise dos serviços ecossistêmicos para a formulação de políticas preservacionistas e de conservação deve levar em consideração a interação multiescalas, demonstrando as consequências e a distribuição dos serviços nos mais diversos níveis espaciais possíveis (RUHL; KRAFT; LANT, 2007).

A título ilustrativo, Ruhl, Kraft e Lant(2007) demonstram a interação multiescalas existente em uma floresta, que vai desde o nível da folha até o do biomaque pertence a este ecossistema. Da escala de nível mais abrangente até a mais específica há a determinação das condições ambientais (determination of environmental conditions), isto é, estabelecimento das características ambientais do ambiente que possibilitam a existência desses componentes. No sentido contrário, do nível mais específico até o mais abrangente vai se criando a estrutura que sustenta o ecossistema em análise (chamado de emergent properties). A figura abaixo ilustra a interação entre as escalas:

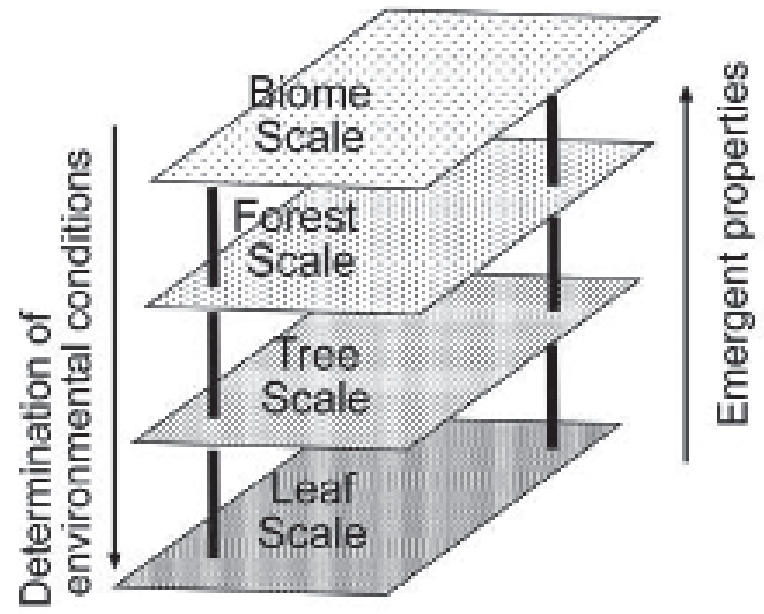

Fonte: RUHL; KRAFT; LANT, 2007.

Além da escala espacial, a escala temporal também é importante para se analisar os serviços ecossistêmicos. A análise temporal fazse necessária, visto que processos ecológicos ocorrem em diferentes velocidades, conforme o ecossistema, seus componentes, seu clima. Processos rápidos são mais fáceis de serem percebidos do que processos 
mais lentos (período de cheia de um rio pode ser considerado um processo rápido, pois é facilmente perceptível, enquanto os efeitos da erosão são mais lentos e percebíveis a longo prazo). Assim como as escalas espaciais, as escalas temporais devem ser analisadas de forma conjunta (tanto aquelas que identificam processos rápidos, quanto as de processos mais lentos), pois efeitos a longo prazo nos ecossistemas afetam os mais rápidos e viceversa (RUHL; KRAFT; LANT, 2011).

A geografia dos serviços ecossistêmicos analisa como as diferentes escalas (espaciais e locais em seus diversos níveis) interagem entre si. Analisando-se essas interações, é possível entender como os serviços ecossistêmicos são produzidos, qual o caminho tomado e como são disponibilizados para a população (SALZMAN, 2010).

1.3. Valoração dos serviços ecossistêmicos: definir sua importância ou a forma de modificar a natureza

Como já visto, serviços ecossistêmicos possuem um valor econômico muito importante para o bem-estar do ser humano. Nas palavras de Constanza (1997), a valoração dos serviços ecossistêmicos é inerente às escolhas e decisões ambientais que se faz. Na acepção do autor, a valoração faz parte de qualquer decisão, pois "enquanto nós somos forçados a fazer escolhas, passamos por um processo de valoração". Ao tomar uma decisão, querendo ou não, está-se valorando e a única escolha que não pode ser feita é querer se decidir ou se manter inerte!

Constanza (1997) estipulou a valoração dos serviços ecossistêmicos com base nas mudanças que estes sofrem e os seus reflexos na atividade humana ${ }^{9}$. Mudanças na qualidade e na quantidade dos serviços disponíveis causam tanto um impacto no bem-estar da população humana quanto dentro dos próprios ecossistemas, alterando a disponibilidade de capital natural. As percepções dessas mudanças ficam mais claras para determinados serviços que já possuem algum mercado. Como exemplo, pode-se mencionar os corais, que auxiliam na criação e na procriação de peixes, atividade que possui um valor de mercado por conta da pesca de frutos-do-mar; e, também, pode-se mencionar as florestas, que possuem serviços de provisão ao fornecer material, como a madeira, atividade que $9 \mathrm{O}$ autor, de forma ilustrativa, tentou valorar os serviços ecossistêmicos em todo o mundo, chegando ao valor médio abstrato de US\$ 33 trilhões, correspondente a 1,8 vezes o valor do PIB daquela época. O próprio autor admite que este valor não deve ser levado em consideração como o valor exato dos serviços ecossistêmicos, mas, sim, para demonstrar a importância dos serviços para a humanidade (CONSTANZA, 1997, p. 257-259). 
possui um mercado bem- estabelecido.

Um dos maiores problemas da valoração desses serviços está nas chamadas falhas de mercado (market failures). Quando não há valoração desses serviços, corre-se o risco de não lhes dar a proteção necessária, ou não definir seus limites de uso (RUHL; KRAFT; LANT, 2007). Este problema demonstra a subvaloração (CARVALHO, 2015)desses serviços ${ }^{10}$, pois a inexistência de um mercado ou uma precificação, muitas vezes, impede o reconhecimento da importância de determinado serviço. Isso se dá, sobretudo, pelo fato de os serviços serem recursos abertos (open-access resources), dando a ideia de serem gratuitos e ilimitados, (RUHL; KRAFT; LANT, 2007) quando não o são (ARAGÃO, 2011). A gratuidade e a suposta disponibilidade ilimitada dos serviços tendem a causar o que Ruhl, Kraft e Lant(2008) denominam de Tragédia dos Serviços Ecossistêmicos ${ }^{11}$, tornando escassos (até mesmo degradando completamente) os serviços produzidos.

O motivo para esses serviços não possuírem um valor é que eles não são facilmente percebíveis como serviços ecossistêmicos pelo ser humano (CONSTANZA, 2014), como o ar que se respira, o clima de determinada região, ou o acesso a uma determinada região. Não se sabe que, na verdade, estes são benefícios originados de funções e processos dos ecossistemas e que eles possuem um valor econômico com um determinado fim para o ser humano.

Outro problema para a valoração desses serviços é que eles possuem um valor e uma importância específica conforme o local analisado (SALZMAN, 2010). O mesmo serviço pode ter um valor em determinada região, enquanto em outra possui outro valor distinto, por alterações das condições climáticas, geográficas e sociais.

Destaca-se que o método de valoração mais comum é o monetário,

10 Quanto à subvaloração, é, também, a doutrina de Alexandra Aragão: “(...) é sabido que o valor de mercado dos recursos naturais não reflectecorrectamente o seu real valor: a floresta não vale só pela lenha, mobília ou pasta de papel que pode produzir, tal como o rio não vale só pelos peixes e pela água para abastecimento. Mas o real valor, social e ecológico, dos recursos naturais vai muito além do seu valor de mercado. O real valor resulta tanto da própria existência do recurso, como das funções naturais desempenhadas e que são os tais serviços prestados ao Homem e ao Planeta". (ARAGÃO, 2011, p. 8).

11 Conceito inspirado na Tragédia dos comuns de Garret Hardin (1968), em que a falta de informação e de controle sobre bens acaba por reduzir sua disponibilidade. No caso dos serviços ecossistêmicos, a ideia de serem, muitas vezes, externalidades positivas (o proprietário da área que produz serviços ecossistêmicos para o exterior não recebe nenhum ganho quando outros se utilizam desses bens), assim como a falta de uma valoração desses serviços e a inexistência de incentivos e políticas que auxiliem na manutenção dos serviços sem que uma pessoa apenas se responsabilize pelo interesse coletivo, podem incentivar a exploração excessiva do serviço, deixando-o, inclusive, inutilizável para as próximas gerações (RUHL; LANT; KRAFT, 2008). 
quando se tenta atribuir uma quantia em dinheiro ao serviço ecossistêmico analisado. Ocorre que este método encontra grandes problemas ao se pretender atribuir um valor econômico para serviços ecossistêmicos que não possuem um mercado determinado (falhas de mercado). Em vista disso, existem alguns métodos de valoração que levam em consideração certos critérios para atribuição de valor como, por exemplo, a comparação dos serviços ecossistêmicos com serviços manufaturados, a importância para a comunidade de um determinado ecossistema ou a identificação do valor que as pessoas estariam dispostas a pagar para manter determinado serviço. Autores como Ruhl, Kraft e Lant (2007) apontam para falhas existentes nesses métodos, por conta de omitirem alguns critérios que seriam importantes para a valoração dos serviços. Destacam os autores que esses métodos dificilmente levam em consideração toda a complexidade dos serviços ecossistêmicos, ou pecam por aplicar a mesma fórmula de valorações de bens manufaturados nos serviços ambientais, cujas características são distintas.

Essa valoração monetária, por sua vez, poderia ser vista como uma maneira de comodificação da natureza (CONSTANZA, 2014), ou de precificar algo que possui um valor inestimável (o meio ambiente). Entretanto, não é essa a ideia, pois a valoração de recursos naturais já é uma prática comum para determinados serviços ecossistêmicos. A madeira, por exemplo, possui um preço de mercado conhecido. Podemos mencionar, também, que recursos naturais são objetos de processos de compensação ambiental $^{12}$, durante trâmites de autorização para a construção de empreendimentos, por exemplo.

Constanza (2014) entende que a atribuição de valor monetário aos serviços ecossistêmicos não os torna comodificáveis ou privatizados, pois não se valora o custo pela possibilidade de substituir os serviços, mas sim pelo seu uso e não uso. Além disso, o autor entende que a valoração em dinheiro torna a decisão mais transparente, inclusive para o reconhecimento de incertezas e limitações existentes. Reconhecer e mensurar monetariamente os serviços ecossistêmicos retira a ingenuidade humana de determinados conceitos, pois os estudos sobre serviços ecossistêmicos têm revelado as limitações da infraestrutura construída pelo homem (também chamada de

12 As medidas compensatórias autorizadas pelo órgão ambiental competente, quando se apresenta um Estudo de Impacto Ambiental, durante o licenciamento ambiental, para o qual o impacto causado pelo empreendimento fique "[...] dentro de um limite aceitável [...] não colocando em risco o meio ambiente e a qualidade de vida da coletividade" (grifo nosso) (FARIAS, 2015, p. 97). Ou seja, destacando-se quais ecossistemas e serviços serão afetados e quanto valeria sua compensação. 
infraestrutura cinza e infraestrutura social) que podem ser aperfeiçoadas com o uso dos serviços ecossistêmicos ${ }^{13}$.

A principal ideia por trás da valoração dos serviços ecossistêmicos, já apontada por Constanza (1997) e Daily (1997) na década de 1990 ou pelo Millennium EcosystemAssessment (2005), é a de que estes possuem um valor vital para o bem-estar humano. E existem critérios sociais, ecológicos e econômicos que devem ser levados em consideração ao se valorar os serviços ecossistêmicos. Por isso, estudos multidisciplinares aprofundados, apontando os possíveis beneficiários, devem ser realizados para a valoração dos serviços ecossistêmicos (RUHL; KRAFT; LANT, 2007). Ademais, não apenas para fins mercadológicos, a valoração pode ser usada para fins múltiplos, auxiliando as decisões ambientais quanto à manutenção dos recursos naturais (CONSTANZA, 2014). E, também, conforme Daily, serviços ecossistêmicos demonstram que "[...] não protegemos o que não valoramos" (DAILY, 1997, p. xix), pois oferecem uma percepção dos ecossistemas que, tradicionalmente, não é quantificada.

Além do método econômico-monetário de valoração, outras formas podem ser utilizadas, como unidades de medidas (hectares), quantidade de energia e escalas temporais. A escolha da forma de valoração passa a ser a que "[...] melhor se comunica para diferentes audiências em um contexto específico decisório" de questões ambientais. (CONSTANZA, 2014, p. 153).

A importância de se estipular um valor econômico aos serviços ecossistêmicos está no fato de se possibilitar compará-los com outros serviços e produtos para se tomar uma decisão mais eficiente sobre a manutenção, recomposição ou deslocamento de ecossistemas. As formas de se valorar os serviços, apesar de serem limitadas, conseguem demonstrar que os serviços não são gratuitos (ARAGÃO, 2011), possuindo um importante valor para a sociedade (RUHL; LANT; KRAFT, 2007).

Nas palavras de Alexandra Aragão, a importância da valoração dos serviços ecossistêmicos se dá porque: “[...] o mercado só consegue

\footnotetext{
$13 \mathrm{O}$ autor menciona estudos que comprovam a capacidade mitigadora de serviços ecossistêmicos (banhado) mais efetiva do que a de um dique em casos de tempestades, em caso de ocorrência de furacão. Além de mitigar o impacto de um evento catastrófico, o mesmo banhado é responsável por estocar carbono, ou seja, o banhado torna-se muito mais eficiente do que um dique. E ter esse conhecimento ilustra a importância dos serviços ecossistêmicos para a humanidade. Naspalavras do autor: "Pointing out that the 'horizontal levees' of coastal marshes are more cost-effective protectors against hurricanes than constructed vertical levees (Constanza et al., 2008) and that they also store carbon that would otherwise be emitted into the atmosphere (Luisetti et al., 2011) implies that restoring or recreating them for this and other benefits is only using our intelligence and ingenuity, not betting against it" (grifonosso) (CONSTANZA, 2014, p. 154).
} 
orientar a utilização para um nível óptimo se o preço reflectir o seu valor social e ecológico". E, quanto à característica aberta dos serviços e à possibilidade de ocorrer a tragédia dos serviços ecossistêmicos, menciona a autora: "[p]orém, muitos dos serviços dos ecossistemas são valorados a preço zero, o que invariavelmente leva a um excesso de utilização e, portanto, a uma afectação pouco eficiente de recursos" (ARAGÃO, 2011, p. 7).

No mesmo sentido, Keith Hirokawa (2015) explica que já é possível estabelecer valores que antes não eram contabilizados por ignorarem ou desconhecerem funções e benefícios dos ecossistemas para os seres humanos. Para o autor, a importância de se conhecer esses valores serve para se ter conhecimento das consequências que as mudanças decorrentes da degradação dos ecossistemas geram no bem-estar da humanidade, justificando a importância de conservar os serviços e seus ecossistemas evitando prejuízos futuros (escassez de alimentos, aumento de ocorrência de desastres ambientais etc). A estipulação de valores aos serviços ecossistêmicos possibilita a criação de informação acerca desses serviços $^{14}$ (HIROKAWA, 2015, p. 551).

A economia dos serviços ecossistêmicos contribui para a análise dos benefícios, do custo das perdas e dos efeitos das medidas de proteção dos serviços ecossistêmicos (ARAGÃO, 2011). A informação obtida com a valoração dos serviços ecossistêmicos tem um papel fundamental para estabelecer quais são os serviços que se pretende preservar e como os serviços contribuem com o bem-estar dos seres humanos. Além de auxiliar na valoração, a informação contribui, também, no entendimento das complexidades e das interconectividades existentes entre os serviços ecossistêmicos (RUHL, RAFT, LANT, 2007).

\section{Serviços ecossistêmicos e seus efeitos nos sistemas jurídicos}

Nesta interação dinâmica, o Direito tem um papel fundamental como garantidor de um direito fundamental ao meio ambiente equilibrado ${ }^{15}$, garantindo-se o valor constitucional de um Estado Ambiental (CARVALHO, 2013). Neste viés, os serviços ecossistêmicos devem ser pensados como 14 A informação sobre os serviços ecossistêmicos auxilia na valoração de serviços perdidos, ou seja, contabiliza o dano causado ao meio ambiente em decorrência de impactos que o degradam (desastres, degradação), conforme (HIROKAWA, 2011, p. 553).

15 Art. 225 da Constituição Federal: Todos têm direito ao meio ambiente ecologicamente equilibrado, bem de uso comum do povo e essencial à sadia qualidade de vida, impondo-se ao Poder Público e à coletividade o dever de defendê-lo e preservá-lo para as presentes e futuras gerações 
objeto de proteção e regulação, a partir da intercomunicação entre sistemas distintos, auxiliando na formação de critérios jurídicos para a proteção (CARVALHO, 2010).

Atualmente, o Direito Ambiental tem se utilizado da noção de serviços ecossistêmicos para a regulação e o planejamento ambiental. A seguir, serão tratados dois casos específicos: a questão dos pagamentos por serviços ambientais e o gerenciamento de risco de desastres conjugado com serviços ecossistêmicos a partir da noção de infraestruturas verdes.

\subsection{O pagamento por serviços ambientais}

A política do pagamento por serviços ambientais - PSA consiste em um conceito básico de mercado: uma parte aceita tomar certas atitudes para manter a produção de algum serviço ecossistêmico, enquanto outra oferece um incentivo para isso (SALZMAN, 2010). Trata-se de internalizar as externalidades positivas geradas pelos serviços ecossistêmicos (benefícios que não são contabilizados para os geradores dos serviços e vistos como gratuitos e ilimitados pelos beneficiários) por meio de remuneração/incentivo ao gerador do serviço, caracterizando-se como "[...] um complemento aos atuais instrumentos de comando e controle, com o objetivo de tornar efetiva a tarefa de preservação ambiental" (ALTMAN, 2011 p. 74) ${ }^{16}$. Não existindo algum estímulo para conservar os serviços, eles poderão desaparecer, podendo ocorrer a tragédia dos serviços ecossistêmicos (RUHL; LANT; KRAFT, 2008).

É uma ideia originada do princípio poluidor-pagador, com um aspecto positivo preservacionista, chamado de princípio do protetorrecebedor (ARAGÃO, 2011). A ideia de protetor-recebedor segue a mesma lógica do poluidor-pagador; no entanto, conforme já mencionado, as externalidades positivas são internalizadas na conduta do protetor, na forma de incentivos ou pagamento.

Partindo-se da premissa de que quem polui deve arcar com os custos dos danos ambientais causados (externalidades negativas, prejuízos causados a terceiros pela atividade poluidora) como uma forma de não incentivo à continuidade da atividade, aquele que preserva e gera ganhos sociais (produz externalidades positivas, ou seja, ganhos sociais para

16 Os serviços ecossistêmicos são considerados externalidades positivas, pois são bens públicos de uso comum, para cuja manutenção não existiria uma forma de se pagar (RUHL; KRAFT; LANT, 2007). No mesmo sentido, Nusdeo (2012, p. 72) classifica as externalidades positivas como sendo os "[...] benefícios a terceiros que não são recuperados pelo agente que as produziu". 
terceiros, sem receber pagamento) deve receber incentivos pela manutenção de seu comportamento protecionista (ARAGÃO, 2011).

O contrato do PSA pode ser feito entre privados (proprietários de áreas onde existem serviços ecossistêmicos e locais onde os benefícios são distribuídos), tendo um ou mais proprietários exigindo a conduta de que o provedor do serviço se obrigue em preservá-lo. Ou, também, pode ser feito entre proprietários privados e o poder público, sendo este o administrador ou facilitador da negociação. Os PSAs podem ser estabelecidos de forma dinâmica, variando conforme a característica do(s) serviço(s) ecossistêmico(s) existente(s) (ALTMAN, 2011, p. 77).

A ideia de se pagar para preservar os serviços ecossistêmicos não é tão recente no ordenamento jurídico. Pode-se destacar que a Política Nacional de Meio Ambiente já previa a utilização de instrumentos econômicos para promover a proteção do meio ambiente ${ }^{17}$. Nesse sentido, menciona Carvalho (2015, p. 59):

Os serviços ambientais e seu respectivo pagamento encontram aderência ao sistema jurídico pátrio por estarem compreendidos na noção de instrumentos econômicos, como mecanismos de implantação da Política Nacional de Meio Ambiente (art. 9, XIII, Lei n. 6.938/81).

Outras leis federais também mencionam a possibilidade de se criar incentivos econômicos visando à proteção ambiental. É o caso das florestas, abordado no capítulo X do Código Florestal (Lei 12561/2012), em que se prevê o "Programa de Apoio e Incentivo à Preservação e Recuperação do Meio Ambiente" (art. 41) que promove o "[...] pagamento ou incentivo a serviços ambientais como retribuição, monetária ou não, às atividades de conservação e melhoria dos ecossistemas e que gerem serviços ambientais" (inciso I).

No inciso mencionado, são arroladas diversas atividades de conservação que podem ser retribuídas com o pagamento monetário ou de outra forma. São elas: (i) o sequestro, a conservação, a manutenção e o aumento do estoque e a diminuição do fluxo de carbono; (ii) a conservação da beleza cênica natural; (iii) a conservação da biodiversidade; (iv) a conservação das águas e dos serviços hídricos; (v) a regulação do clima; (vi) a valorização cultural e do conhecimento tradicional ecossistêmico; (vii) a conservação e o melhoramento do solo; (viii) a manutenção de Áreas de Preservação Permanente, de Reserva Legal e de uso restrito.

17 “Art. 9 - São Instrumentos da Política Nacional do Meio Ambiente: (...) XIII - instrumentos econômicos, como concessão florestal, servidão ambiental, seguro ambiental e outros". 
Apesar de não especificar de que forma serão realizados os pagamentos e incentivos ${ }^{18}$, a legislação florestal já demonstra a intenção de se incentivar práticas conservacionistas que focam na preservação e manutenção de serviços ecossistêmicos por meio de remuneração ou incentivos. Percebe-se uma descaracterização da preservação do meio ambiente apenas por meio de coerção (multas, embargo de obra, demolição), incluindo-se o incentivo às boas práticas.

O PSA é uma forma já estabelecida no Brasil ${ }^{19}$ para auxiliar na proteção e na regulação dos serviços ecossistêmicos, oferecendo incentivos (monetários ou não) aos seus protetores. Trata-se de uma maneira de destacar a importância de se proteger esses serviços e, ainda, tentar quantificá-los em um determinado valor que sirva como um estímulo à manutenção e preservação dos ecossistemas.

E o Direito surge neste momento como regulador e garantidor, auxiliando no cumprimento e na proteção desses serviços, seja pela formulação de legislações, ou por meio de coerção para se fazer cumprir os contratos de PSA.

\subsection{A infraestrutura verde na prevenção de risco de desastres}

18 Para uma crítica aos dispositivos legais mencionados, ver a obra de Paulo de Bessa Antunes, que menciona: “(...) o conjunto de medidas verbalizadas na lei, sem uma clara indicação de seu custeio e das repercussões para o conjunto da sociedade, implicam em transferência de renda que deveria ser bem explicada, de forma que a sociedade com ela concordasse ou discordasse" (ANTUNES, 2014, p. 262).

19 No âmbito federal, tramita na Câmara dos Deputados o Projeto de Lei no 792/2007, que "define os serviços ambientais e prevê a transferência de recursos, monetários ou não, aos que ajudam a produzir ou conservar estes serviços". O projeto é de relatoria do Deputado Federal Anselmo Jesus (PT/RO) e tem como objetivo "transferir recursos, monetários ou não monetários, para aqueles que ajudam a conservar ou produzir" serviços ecossistêmicos (chamados aqui de serviços ambientais).

O texto original do projeto possui somente quatro artigos, em que, no primeiro deles, classificamse os serviços ambientais, de forma semelhante à classificação do MillenniumEcosystemAssessment, dividindo-os em quatro categorias. O segundo artigo estabelece que quem empregar esforço para desenvolver os serviços fará jus ao pagamento ou compensação determinada. O terceiro artigo estabelece que caberá ao Executivo regulamentar a lei que dispõe sobre os serviços ecossistêmicos. $\mathrm{O}$ quarto artigo apenas dispõe sobre a vigência da lei.

A lei não apresenta muitos detalhes de como serão realizados os pagamentos ou quem poderá recebêlos, classificando todos os recebedores de uma forma genérica. Sem contar que passa a responsabilidade de regulamentação da lei para o Poder Executivo. Ou seja, o projeto de lei não especifica os detalhes sobre as formas de proteção e conservação, nem como serão feitos os pagamentos.

Vários municípios possuem legislações que estabelecem o programa de pagamento por serviços ambientais. Criam fundos ou formas de investimento para pagar os proprietários que mantiverem os serviços intactos. Os municípios de Campinas-SP (Lei Municipal no 15.046 de 23 de julho de 2015) e o município de Extrema-MG que, desde 2007, criou o "Projeto Conservador de Águas", incentivando os agricultores a protegerem os serviços ecossistêmicos, por meio de pagamentos e incentivos, por exemplo. 
Outra forma de proteção jurídica dos serviços ecossistêmicos é a sua observação como infraestrutura verde, utilizada, como será visto, na prevenção e mitigação de desastres ambientais, principalmente aqueles decorrentes de eventos climáticos extremos.

O conceito habitual que se tem de infraestrutura é o de mecanismos construídos pelo ser humano, através da Engenharia Civil (CARVALHO; DAMACENA, 2013), como pontes, diques, barragens, pistas, aeroportos, entre outros, as chamadas infraestruturas cinzas. Infraestrutura também pode ser instalação ou prédio, como é o caso de hospitais, escolas e prisões, as infraestruturas sociais (BENEDICT; McMAHON, 2001). Todas essas infraestruturas são construções do ser humano que facilitam e auxiliam a vida das pessoas.

A natureza, por sua vez, também pode ser considerada como infraestrutura, pois fornece serviços e produtos que auxiliam na continuidade e no desenvolvimento da sociedade, as chamadas infraestruturas verdes. A infraestrutura verde se assimila à infraestrutura construída por fornecer serviços ecossistêmicos necessários para a manutenção da vida humana e do seu bem-estar. O fornecimento é dado pelos serviços ecossistêmicos como, por exemplo, o fornecimento de proteínas através de alimentos, medicamentos advindos da biodiversidade ou a proteção contra chuvas e inundações (VERCHICK, 2012).

O termo infraestrutura verde se refere a uma rede interconectada de áreas verdes que conservam ecossistemas e suas funções que auxiliam populações humanas. A noção de infraestrutura verde não se dá somente sobre uma unidade isolada, mas sim sobre áreas que estão conectadas com aquela, formando uma infraestrutura, porém, de recursos naturais. A ideia de infraestrutura reflete a complexidade dos ecossistemas e de seus serviços, conforme já relatado. Áreas conectadas conseguem ser muito mais úteis e completas do que áreas protegidas de forma isolada, pois conseguem preservar plantas nativas, animais e processos ecológico ${ }^{20} \mathrm{de}$ uma forma sustentável, em conjunto com o desenvolvimento da sociedade, e não fragmentada (BENEDICT; McMAHON, 2001).

Assim como é feito com as infraestruturas construídas, as infraestruturas verdes também precisam de planejamento a longo prazo

20 Art. 225. Todos têm direito ao meio ambiente ecologicamente equilibrado, bem de uso comum do povo e essencial à sadia qualidade de vida, impondo-se ao Poder Público e à coletividade o dever de defendê-lo e preservá- lo para as presentes e futuras gerações.

$\S 1^{\circ}$ Para assegurar a efetividade desse direito, incumbe ao Poder Público:

I - preservar e restauraros processos ecológicos essenciais e prover o manejo ecológico das espécies e ecossistemas (grifo nosso). 
e de constante manutenção. A construção de uma estrada, um aeroporto, uma escola, ou um hospital, por exemplo, não é feita sem um estudo aprofundado e uma análise dos custos necessários para realizar o projeto. Com a infraestrutura verde o mesmo acontece. É preciso planejamento, estudo e informação para evitar uma ocupação irregular e insustentável dos bens naturais. A modificação humana dos ecossistemas sem o devido planejamento fragmenta e empobrece o ecossistema além de causar diversos malefícios à própria humanidade. Isso se reflete nos serviços ecossistêmicos, afetando a capacidade de controle de inundações, o fornecimento de materiais de construção e alimentos necessários para vida humana, bem como o acesso a lugares que abrigam e protegem. Os efeitos também são sentidos econômica e socialmente, como, por exemplo, nos custos de mitigação e respostas de desastres e na necessidade de se fazer altos investimentos para construção de infraestruturas que substituam aquelas perdidas (naturais e/ou construídas). Muitas vezes, o custo de se preservar e manter áreas verdes é muito menor do que aqueles gastos com a compensação pelos danos sofridos em áreas com poucos ou sem serviços ecossistêmicos existentes (BENEDICT; McMAHON, 2001).

Para Verchick (2012), pensar nos ecossistemas como infraestruturas verdes pode auxiliar-nos na elaboração de políticas públicas de diversas formas. Primeiramente, esta perspectiva destaca os diversos serviços ecossistêmicos que os ecossistemas fornecem, facilitando e encorajando a elaboração e a busca por maneiras de proteger aqueles de que mais precisamos. Reconhecer quais são os serviços essenciais também é uma forma de valoração, conforme já dito por Constanza (1997; 2014), e isso auxilia na construção de informação para a elaboração de políticas de proteção mais eficientes.

Pode-se mencionar, a título exemplificativo, trecho do voto do Recurso Especial 650.728 - SC ${ }^{21}$ que fala sobre a evolução da cultura 21 Conforme trecho do voto do Ministro: "Não obstante sua relevante posição de ecossistema-transição entre o ambiente marinho, fluvial e terrestre, os manguezais lato sensu (= manguezais stricto sensu e marismas) foram, por equívoco, menosprezados, popular e juridicamente. Em decorrência disso, por séculos prevaleceu entre nós a concepção cultural distorcida que neles enxergava o modelo consumado do feio, do fétido e do insalubre, uma modalidade de patinhofeio dos ecossistemas ou antítese do Jardim do Éden. Daí serem considerados terra improdutiva e de ninguém, associados à procriação de mosquitos transmissores de doenças graves, como a malária e a febre amarela. Um ambiente socialmente desprezível, tanto que - como terrenos baldios - ocupado pela população mais humilde, na forma de palafitas, sinônimo de pobreza, sujeira e párias da sociedade (zonas de prostituição e atividades ilícitas).

Resultado da evolução do conhecimento científico e de mudanças na postura ética do ser humano frente à Natureza, atualmente se reconhecem nos manguezais várias funções.

(...)

A legislação brasileira atual reflete a transformação científica, ética, política e jurídica que reposicio- 
de proteção dos manguezais, que antes eram vistos como ambientes sujos e indesejados, e serviam apenas para a procriação de mosquitos e desenvolvimento de doenças, inclusive com o apoio do Poder Público, para que fossem destruídos. Entretanto, com o desenvolvimento ético, científico e jurídico, percebeu-se que esses ecossistemas possuem diversos serviços e funções que contribuem com o desenvolvimento da sociedade, como áreas reprodutivas de diversas espécies; filtros que retêm nutrientes, sedimentos e poluentes; áreas de proteção contra tempestades e contra erosão da costa. Fonte de alimento e de atividades tradicionais como a pesca artesanal, funcionando, também, como ambiente essencial para a sobrevivência de comunidades tradicionais, o ecossistema foi classificado como de Área de Preservação Permanente pela legislação.

Neste exemplo mencionado, o conhecimento das funções e dos serviços fornecidos pelos manguezais possibilitou uma mudança na política de proteção desses ecossistemas. Essa mudança, literalmente, transformou aquilo que era considerado como sujo e desnecessário em um ecossistema de importância vital, no qual é proibida qualquer intervenção humana.

Em seguida, Verchick (2012) relata que a ideia de infraestrutura torna evidente que os serviços são sistemas interconectados e realizam funções em conjunto, como já explicado anteriormente. Essa perspectiva revela a importância de não se fazer uma proteção isolada, pois outras áreas e regiões verdes (como corredores ecológicos, estuários, por exemplo) fazem parte de uma mesma infraestrutura (problemas de escalas e limites, conforme já mencionado).

E, em terceiro lugar, o autor menciona que as infraestruturas verdes possuem a característica de serem abertas, de uso comum. Visão esta, como já dito, que precisa ser alterada para que não ocorra atragédia dos serviços ecossistêmicos.

No mesmo sentido, quanto à infraestrutura verde, Carvalho entende que "[p]ensar os serviços ambientais como infraestrutura verde atribui um maior destaque à integração entre os elementos ambientais e aqueles construídos pelo homem". Para o autor, este conceito valoriza os serviços ecossistêmicos fornecidos para a vida humana e integra valores de

nou os manguezais, (...) o legislador atribuiu-lhes natureza jurídica de Área de Preservação Permanente" (grifo nosso).

BRASIL. SUPERIOR TRIBUNAL DE JUSTIÇA. Recurso Especial 650728/SC. Recorrente: H Carlos Schneider S/A Comércio E Indústria E Outro; Recorrido: Ministério Público Federal. Relator: Ministro Herman Benjamin. Brasília, 23 de outubro de 2007. Disponível em: <https://ww2.stj.jus.br/processo/ $\underline{\text { revista/inteiroteor/?num registro }=200302217860 \& d t \text { publicacao }=02 / 12 / 2009>}$. Acessoem: 18 ago. 2015. 
“conservação, ordenação e planejamento de ocupação do solo, gestão do crescimento e planejamento da infraestrutura construída" (CARVALHO, 2015, p. 58).

A visão de infraestrutura também encoraja uma maior valorização do monitoramento, da manutenção e da recuperação destas áreas" (grifo do autor). A título exemplificativo, o autor cita áreas alagadas, marismas, dunas e restingas em comparação com barragens, diques e estradas para demonstrar o que são as infraestruturas naturais. Em um momento de ocorrência de desastre, conforme explica o autor, essas infraestruturas verdes podem lidar com o evento em dois momentos. Em um primeiro momento, "atuando como um bloqueio natural aos impactos de um desastre, diminuindo ou desviando as forças da natureza da direção das comunidades humanas" (grifo do autor). Em um segundo momento, após o evento, "a infraestrutura natural servirá para prover bens e serviços de fundamental importância para a recuperação econômica e fisica do local atingido". Ou seja, em um momento de desastre, as infraestruturas verdes mencionadas auxiliarão na mitigação e prevenção do dano fornecendo serviços ecossistêmicos de regulação e, posteriormente, com serviços de provisão (CARVALHO, 2015, p. 61).

A noção de infraestrutura verde requer uma visão mais cuidadosa para a gestão e uso do solo. Neste caso, destaca-se o protagonismo dos municípios para que se faça essa gestão, determinada pela Constituição Federal (art. 30, VIII) (CARVALHO, 2015, p. 78-79). Visando à redução do risco de desastres, a inclusão dos serviços ecossistêmicos mostra-se como uma alternativa ambientalmente mais segura e economicamente mais barata para tanto.

\section{3. fundamentação para a proteção jurídica dos serviços ecossistêmicos: os oito princípios de J.B. Ruhl e suas aplicações}

Conforme demonstrado, o contexto jurídico brasileiro já apresenta algumas alternativas para proteger os serviços ecossistêmicos. Porém, para auxiliar o desenvolvimento de novas formas de proteção (ou aprimorar as existentes) serão citados os oito princípios criados por J. B. Ruhl para auxiliarem na elaboração de um escopo com o qual poderá se trabalhar para gerenciar serviços ecossistêmicos (RUHL, 2015). São eles: 
Princípio um - Serviços ecossistêmicos sempre deverão criar o bem-estar humano: conforme já mencionado, quando se fala em serviços ecossistêmicos, fala-se, estritamente, da existência de correspondência do componente humano. Quando se criar medidas de uso (PSA) e proteção dos serviços ecossistêmicos, deve-se sempre destacar o que eles fazem para a humanidade.

Quando não houver uma pessoa ou uma comunidade que se beneficia de algum produto originado dos ecossistemas, estar-se-á falando de capital natural, ou do próprio ecossistema em si, mas não em serviços ecossistêmicos. Ruhl, Kraft e Lant (2007), bem como Constanza (1997) e Gretchen (1997) já diziam que somente existirão serviços ecossistêmicos quando existir o respectivo beneficio humano.

Princípio dois - definir direitos de propriedade e uma distribuição de impactos equitativa: neste caso, deve-se destacar como os geradores de capital natural e os beneficiários de serviços ecossistêmicos podem ser incentivados ou obrigados a tomar determinadas condutas. Esse princípio possui vital importância para o PSA, pois deve ser determinado quando um dado proprietário poderá receber face à manutenção dos serviços ecossistêmicos e qual área de sua propriedade deverá ser protegida (e, assim, impedida de ser utilizada para outros fins).

Hirokawa (2011), no mesmo sentido, entende que, ao se regular os serviços ecossistêmicos, o direito de propriedade irá,inevitavelmente, ser atingido e deverá ser adaptado. Novas questões acerca de como definir quem teria a legitimidade de obrigar outro proprietário a manter e preservar determinado ecossistema (pois é um fornecedor de serviços ecossistêmicos) em um local distinto deverão ser enfrentadas pelo Direito (RUHL, KRAFT, LANT, 2007).

Princípio três - integrar a noção de serviços ecossistêmicos com outras políticas ambientais: políticas de proteção e preservação de serviços ecossistêmicos devem ser criadas de forma complementar a outras políticas preservacionistas já existentes. E as políticas já existentes também deverão passar a incluir a noção desses serviços em seus programas.

A própria noção de serviços ecossistêmicos exige uma abordagem multidisciplinar de diversas áreas a fim de se ter a informação necessária para quem irá decidir. Neste sentido, abre-se uma enorme gama de formas de proteção dos serviços ecossistêmicos e dos ecossistemas, integrando-se a perspectiva de serviços ecossistêmicos (CARVALHO, 2015) a diversas políticas ambientais (DAILY, 2009). 
Princípio quatro - Precificação é o ideal, mas nem sempre o necessário: alguns serviços ecossistêmicos não precisam ser valorados monetariamente. É o caso de serviços que possuem valores inestimáveis (por questões históricas e culturais, por exemplo). Entretanto, se existir alguma forma de se valorar e dar um preço aos serviços, é sempre bom têlos em mente visando-se ter melhores opções para a decisão quanto ao uso e preservação desses serviços.

Como já mencionado, existem diversas maneiras de se valorar os serviços ecossistêmicos, cada uma específica para o fim pretendido (CONSTANZA, 2014). Porém, a monetarização permite se compreender quanto se estaria perdendo economicamente ao se deixar de preservar os serviços ecossistêmicos (CONSTANZA, 1994).

Princípio cinco - Os valores devem ser explícitos: sempre que se tiver que fazer uma decisão que envolve os serviços ecossistêmicos, os valores referentes ao conhecimento desses serviços devem ser sempre apresentados. A importância da informação dos valores e das medidas tomadas para embasar a decisão ambiental deverá ser sempre clara e criteriosa. Justifica-se isso, inclusive, para apresentar possíveis incertezas pelo qual o processo de valoração passou (CONSTANZA, 2014).

Princípio seis - Incluir serviços ecossistêmicos em Estudos de Impactos Ambientais: diante da importância dos serviços ecossistêmicos parao bem-estar humano, as políticas de desenvolvimento (construções e obras, por exemplo) deverão apresentar em seus Estudos de Impactos Ambientais quais serviços ecossistêmicos serão afetados e de que forma serão compensados. Novamente, o protagonismo da informação. Verificar quais serviços ecossistêmicos serão afetados e quais medidas compensatórias serão tomadas auxilia na tomada de medidas mais criteriosas, bem como sejam feitas dentro de um limite aceitável (FARIAS, 2015).

Princípio sete - incluir informações sobre serviços ecossistêmicos em decisões ambientais: sempre que possível, quando se tiver que tomar alguma decisão que envolva algum ecossistema (seja de preservação ou de compensação), deve-se informar sobre as consequências desta no bem-estar humano.

Princípio oito - designar cuidadosamente qualquer medida a ser tomada quanto a serviços ecossistêmicos: quando se tomar alguma decisão que leve em consideração os serviços ecossistêmicos, utilizar critérios técnicos confiáveis, bem como realizar a efetiva manutenção para que não haja qualquer prejuízo para as partes. 
Estes dois princípios, por fim, podem ser analisados em conjunto, pois demonstram a importância da multidisciplinariedade nas decisões a serem tomadas (DAILY, 2009), bem como o impacto que as decisões tomadas podem ter nos serviços ecossistêmicos e, consequentemente, no bem-estar humano (CONSTANZA, 1994; MILLENNIUM ECOSYSTEM ASSESSMENT, 2005). Ou seja, abordar serviços ecossistêmicos nas decisões ambientais é uma questão complexa, inerente à própria matéria, que exigirá mudanças no sistema jurídico que, se não tomadas, poderão causar a tragédia dos serviços ecossistêmicos (RUHL, 2008).

\section{CONCLUSÃO}

Serviços ecossistêmicos são os serviços e produtos originados dos ecossistemas que auxiliam no bem-estar humano. O estudo dessa matéria aborda questões complexas, que exigem uma abordagem multidisciplinar de diversas áreas. Neste trabalho analisou-se a importância de se abordar os serviços ecossistêmicos em algumas dessas áreas.

Por uma perspectiva ecológica, busca-se reconhecer quais são os serviços ecossistêmicos existentes em determinado local, como ele é formado e os benefícios produzidos. A perspectiva geográfica permite estabelecer os limites territoriais e temporais dos serviços ecossistêmicos, demonstrando-se qual a origem, o caminho e o destino dos serviços. A geografia dos serviços ecossistêmicos contribui para o entendimento de que serviços ecossistêmicos podem ser observados por meio de diversas escalas (geográficas e temporais) distintas. Quanto à economia dos serviços ecossistêmicos, percebe-se que existem diversas maneiras de se valorar os serviços, destacando-se sua importância para o bem-estar humano. A valoração não deve ser vista como uma precificação dos serviços ou da própria natureza, visto que ela demonstra o valor do uso e do não uso dos ecossistemas, auxiliando na fundamentação da proteção dos serviços ecossistêmicos.

É de suma importância para o sistema jurídico esta perspectiva multidisciplinar dos serviços ecossistêmicos, pois providencia a informação necessária para se ter a devida preservação dos ecossistemas e de seus serviços. No presente trabalho, analisou-se a maneira de se regular (pagamento de serviços ambientais) e de se utilizar os serviços ecossistêmicos como instrumentos de quantificação e ponderação sobre os 
riscos de desastres (infraestrutura verde).

Estes são apenas alguns modelos de proteção jurídica dos serviços ecossistêmicos. Porém, como a própria matéria analisada, a utilização dos serviços ecossistêmicos pelo sistema jurídico passa por uma análise complexa de diversas informações. Em vista disso, apresentaram-se oito princípios-chave para a elaboração de uma política de proteção eficiente e de sua utilização, para que existam fundamentos adequados para a proteção desses serviços.

\section{REFERÊNCIAS}

ALTMAN, Alexandre. Pagamento por serviços ambientais como mecanismo econômico para a mitigação das mudanças climáticas. In: RECH, Adir Ubaldo. Direito e economia verde: natureza jurídica e aplicações práticas do pagamento por serviços ambientais, tais como instrumento de ocupações sustentáveis. Caxias do Sul: EDUCS, 2011 p. 71-96.

ARAGÃO, Alexandra. A natureza não tem preço... mas devia: o dever de valorar e pagar os serviços dos ecossistemas. Disponível em: $<$ https:// estudogeral.sib.uc.pt/jspui/bitstream/10316/17696/1/A\%20natureza\%20n $\% \mathrm{C} 3 \% \mathrm{~A} 3 \mathrm{o} \% 20$ tem $\% 20$ pre $\% \mathrm{C} 3 \% \mathrm{~A} 7 \mathrm{o} \% 20$ Alexandra $\% 20 \% 20 \mathrm{Arag} \% \mathrm{C} 3$ \%A3o\%2025\%20de\%20Outubro.pdf> Acesso em 06 fev. 2017.

BENEDICT, Mark A.; McMAHON, Edward T.Green infrastructure: smart conservation for the $21^{\text {st }}$ century. Washington, D.C.: Sprawl Watch Clearinghouse. 2001, 32 p. Disponível em: <http://www.sprawlwatch.org/ greeninfrastructure.pdf $>$. Acesso em: 04 nov. 2015.

CARVALHO, Délton Winter de. Aspectos epistemológicos da Ecologização do Direito: reflexão sobre a formação de critérios para análise da prova científica. In: André Luíz Callegari; Lenio Luiz Streck; Leonel Severo Rocha. (Org.).Constituição, Sistemas Sociais e Hermenêutica: Anuário do Programa de Pós-Graduação em Direito da Unisinos. Porto Alegre: Livraria do Advogado, 2010, v. 7

CARVALHO, Délton Winter de. Dano Ambiental Futuro: a responsabilização civil pelo risco ambiental. 2. ed. Porto Alegre: Livraria do Advogado, 2013, 248p. 
CARVALHO, Délton Winter de. Desastres ambientais e sua regulação jurídica: deveres de prevenção, resposta e compensação ambiental. São Paulo: Revista dos Tribunais, 2015, 190p.

CARVALHO, Délton Winter de; DAMACENA, Fernanda Dalla Libera. Direito dos desastres. Porto Alegre: Livraria do Advogado, 2013,

CONSTANZA, R.; et al. The value of the world's ecosystem services and natural capital. Nature, Estados Unidos, vol. 387, 253-260, 1997

CONSTANZA, Robert et al. Changes in the global value of ecosystem services. Global environmental change, n. 26, 2014, p. 152-158.

DAILY, Gretchen C.; et al. Ecosystem services in decision making: time to deliver. Frontiers in Ecology and the Environment. Estados Unidos da América, vol. 7, n. 1, p. 21-28, 2009. Disponível em: <http://ssrn.com/ abstract=1397324>. Acessoem 01 jun. 2017.

DAILY, Gretchen C.; et al. Ecosystem services in decision making: time to deliver. Frontiers in Ecology and the Environment. Estados Unidos da América, vol. 7, n. 1, p. 21-28, 2009. Disponível em: <http://ssrn.com/ abstract=1397324>. Acesso em 30 jun. 2017.

DAILY, Gretchen et al. Ecosystem services: benefits supplied to human societies by natural ecosystems issues. Issues in Ecology, n. 2, 1997, p. $1-16$.

FARIAS, Talden. Licenciamento ambiental: aspectos teóricos e práticos. 5 ed. Belo Horizonte: Fórum, 2015.

HARDIN, Garrett. The tragedy of the commons. Science. Estados Unidos, vol. 162

HIROKAWA, Keith. Disaster and ecosystem services deprivation: from Cuyahoga to the Deepwater Horizon. Albany Law Review, Estados Unidos da América, vol. 74, n. 1, p. 543-561, 2011. Disponível em: <http://ssrn. com/abstract=1785345>. Acesso em: 30 jun. 2017.

MILLENIUM ECOSYSTEM ASSESMENT. Ecosystems and Human Well-Being:Synthesis. Washington, DC: Island Press, 2005, 137p.

NUSDEO, Ana Maria de Oliveira. Pagamento por serviços ambientais: 
sustentabilidade e disciplina jurídica. São Paulo: Atlas, 2012, 192p.

RUHL, J. B. In Defense of Ecosystem. Services. Pace Environmental Law Review, n. 32, 2015 p. $306-335$.

RUHL, J. B; KRAFT, Steven E; LANT, Christopher L. The tragedy of ecosystem services. BioScience, n.10, 2008, p. 969-974.

RUHL, J. B; KRAFT, Steven E; LANT, Christopher L. The law and police of ecosystem services. Washington: Island Press, 2007. 360 p.

SAlZMAN, James. Designing Payments for ecosystem services. Perc Policy Series, n. 48, 2010, p. 1-35.

VERCHICK, R. M. Facing catastrophe: environmental action for a postKatrina world. Cambridge: Harvard University Press, 2012, 322p.

Artigo recebido em: 08/09/2017. Artigo aceito em: 25/07/2018.

\section{Como citar este artigo (ABNT):}

SILVA, R. K.; CARVALHO, D. W. APORTES INICIAIS PARA UMA PROTEÇÃO JURÍDICA DOS SERVIÇOS ECOSSISTÊMICOS. Veredas do Direito, Belo Horizonte, v. 15, n. 32, p. 87-115, mai./ago. 2018. Disponível em: <http://www.domhelder.edu.br/revista/index.php/veredas/ article/view/1139>. Acesso em: dia mês. ano. 